\title{
Prevalence of depressive symptoms among older adults who reported medical cost as a barrier to seeking health care: findings from a nationally representative sample
}

\author{
Vinay K. Cheruvu* and Edward T. Chiyaka
}

\begin{abstract}
Background: Older adults aged 65 and over will make up more than 20\% of U.S. residents by 2030, and in 2050, this population will reach 83.7 million. Depression among older adults is a major public health concern projected to be the second leading cause of disease burden. Despite having Medicare, and other employer supplements, the burden of out of pocket healthcare expenses may be an important predictor of depression. The current study aims to investigate whether delay in seeing a doctor when needed but could not because of medical cost is significantly associated with symptoms of current depression in older adults.
\end{abstract}

Methods: Cross-sectional data from the 2011 Behavioral Risk Factor Surveillance System (BFRSS) from 12 states and Puerto Rico were used for this study $(n=24,018)$.

Results: The prevalence of symptoms of current depression among older adults who reported medical cost as a barrier to seeking health care was significantly higher (17.8\%) when compared to older adults who reported medical cost not being a barrier to seeking health care (5.5\%). Older adults who reported medical cost as a barrier to seeking health care were more likely to report current depressive symptoms compared to their counterparts [Adjusted Odds Ratio (AOR): 2.2 [95\% Cl: 1.5-3.3]).

Conclusions: Older adults ( $\geq 65$ years of age) who experience the burden of medical cost for health care are significantly more likely to report symptoms of depression. Health care professionals and policymakers should consider effective interventions to improve access to health care among older adults.

Keywords: Medical cost, Out-of-pocket expenses, Depression, Current depressive symptoms, BRFSS

\section{Background}

The rapid aging of the United States population is due, in part; to the increase in life expectancy and the aging of the post-World War II baby boom generation [1]. By 2030, older adults aged 65 and over will make up more than $20 \%$ of U.S. residents, and by 2050, this population will reach 83.7 million, almost double the 2012 estimated population of 43.1 million $[1,2]$. Older adults are disproportionately affected by chronic conditions with approximately $60 \%$ living with at least one chronic condition and $42 \%$ with at least two chronic conditions [3]. Access to health services is

\footnotetext{
* Correspondence: vcheruvu@kent.edu

College of Public Health, Kent State University, 320 Lowry Hall, 750 Hilltop Drive, Kent, $\mathrm{OH}$ 44242, USA
}

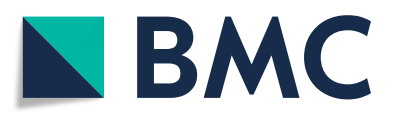

(c) The Author(s). 2019 Open Access This article is distributed under the terms of the Creative Commons Attribution 4.0 International License (http://creativecommons.org/licenses/by/4.0/), which permits unrestricted use, distribution, and

reproduction in any medium, provided you give appropriate credit to the original author(s) and the source, provide a link to the Creative Commons license, and indicate if changes were made. The Creative Commons Public Domain Dedication waiver (http://creativecommons.org/publicdomain/zero/1.0/) applies to the data made available in this article, unless otherwise stated.

essential for prevention and management of chronic illnesses to minimize the disease burden and associated health care costs. The overarching goal of Healthy People 2020 is to improve the health, function, and quality of life of older adults, which includes an objective to increase the proportion of older adults who are up to date on a core set of clinical preventive health services for maintaining quality of life and overall wellness [4].

Depression is a serious problem and a major public health concern among older adults $[5,6]$. The prevalence of depression among community dwelling adults aged 65 and older is estimated to be between 5 and $10 \%$ and is projected to be the second leading cause of disease burden in this population by the year 2020 [7, 8]. Risk factors for 
depression such as chronic diseases [9], disability [10, 11], lack of social support, and socio-economic status [12-14], have been well documented. Given that aging is associated with multiple chronic health conditions and limited financial resources for disease management, and despite the availability of Medicare, Medicaid and employer supplements [15-19], the burden of out of pocket healthcare expenses may be an important predictor of depression.

Although several studies have documented the risk factors for depression in the elderly $[9,10,12-14]$, and while others have examined the impact of depression on healthcare costs [20-22], to the best of our knowledge, out of pocket healthcare expenses (e.g., delay in seeing a doctor when needed but could not because of medical cost) as a predictor of current depressive symptomatology in a nationally representative sample of communitydwelling older adults in the U.S. has not been documented yet. Previous reported research on the association between financial strain and depressive symptoms among older adults focused on financial strain measured by a 4-item scale and was not specific to financial strain due to the burden of out of pocket healthcare expenses $[23,24]$. As such, the purpose of this study is to:

(1) estimate the prevalence of current depressive symptoms in a sample of community dwelling older adults ( $\geq 65$ years of age) who reported a delay in seeing a doctor when needed but could not because of medical cost,

(2) investigate whether delay in seeing a doctor when needed but could not because of medical cost is significantly associated with symptoms of current depression in the elderly after accounting for possible potential confounders, and.

(3) describe the socio-demographic characteristics of older adults who are more likely to report delay in seeing a doctor when needed but could not because of medical cost.

This current study is motivated by "The theory of cost-sharing" framework. Cost-sharing is any kind of out-of-pocket expenses made by individuals for health care services. It may result in individuals' delaying a follow-up health care visit or completely wait out a health problem $[25,26]$. Therefore, we sought to understand the relationship between cost-sharing, as defined by medical cost as a barrier to seeking health care, on symptoms of current depression which is an important health outcome.

\section{Methods}

\section{General study design}

The Behavioral Risk Factor and Surveillance System (BRFSS) is a federally funded telephone survey designed and conducted annually by the Centers for Disease Control and Prevention (CDC) in collaboration with state health departments in all 50 states, Washington, DC; Puerto Rico; the U.S. Virgin Islands; and Guam. The survey collects data on health conditions, preventive health practices, and risk behaviors of the adults selected [27]. All BRFSS questionnaires, data, and reports are available at http://www.cdc.gov/brfss/. Data for this study were obtained from 12 states (Kansas, Louisiana, Maine, Mississippi, Nebraska, Nevada, New Hampshire, New Jersey, New Mexico, New York, Ohio, and Oregon) and Puerto Rico that administered the 'Anxiety and Depression' optional module in the 2011 BRFSS data. The weighted response rates ranged from 33.4 to $61.7 \%$.

\section{Delay in seeing a doctor due to cost: primary exposure of interest}

To determine if cost is a barrier to seeking health care among older adults, responses to the following question: "Was there a time in the past 12 months when you needed to see a doctor but could not because of cost? " were used to create a binary exposure variable (Yes / No).

\section{Current depressive symptoms: primary outcome of interest}

Current depressive symptomatology is defined based on the responses to the eight-item Patient Health Questionnaire (PHQ-8) depression scale [28]. The scores for each item, which range from 0 to 3 , are summed to produce a total score between 0 and 24 points. Symptoms of current depression is defined as PHQ-8 score $\geq 10$ [25]. The PHQ-8 consists of eight of the nine DSM-IV criteria for depressive disorders $[29,30]$.

\section{Covariates of interest}

Socio-demographic variables: age, gender (male, female), race/ethnicity (White non-Hispanic, African American non-Hispanic, Hispanic, Others), marital status (married, unmarried), education (less than college, college graduate), and employment (employed, unemployed); Health indicators: general health ("Excellent / Very good / Good" or "Fair / Poor"), use of special equipment due to a health problem (Yes / No), smoking (Yes / No), and number of chronic conditions other than current depression; and Health care indicators: having a health plan (Yes / No), having a primary care provider (Yes / No), and having an annual checkup (Yes / No), were considered as covariates of interest in this study.

\section{Statistical analyses}

Sampling weights provided in the 2011 BRFSS publicuse data that adjust for unequal selection probabilities, survey non-response, and oversampling were used to account for the complex sampling design and to obtain 
population-based estimates that reflect U.S. non-institutionalized individuals. In order to describe the characteristics of the study population, weighted prevalence estimates, and corresponding 95\% confidence intervals (CI) were computed based on the sample of individuals $(n=24,018)$ with complete data on all variables considered in this study (Fig. 1). Logistic regression models were used to examine if delay in seeing a doctor when needed but could not because of medical cost is significantly associated with symptoms of current depression in the elderly, adjusting for potential confounders and other covariates.

All analyses were conducted in SAS 9.3 (SAS Institute, Cary, NC, USA) using SAS survey procedures (PROC

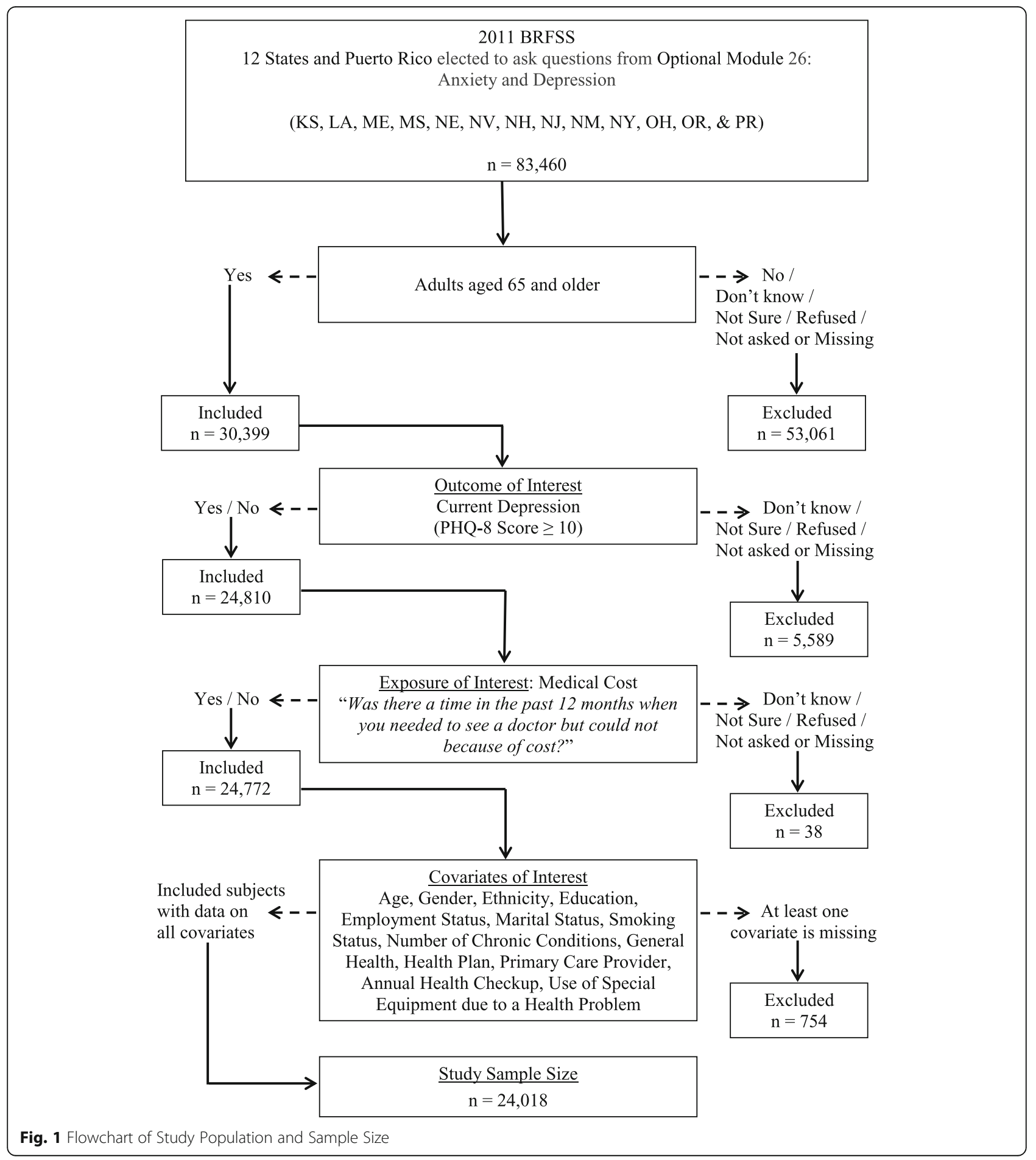


SURVEYFREQ, PROC SURVEYMEANS, PROC SURVEYLOGISTIC) to account for the complex sampling design.

\section{Results \\ Sample characteristics}

In 2011, the prevalence of current depressive symptoms among U.S. older adults from the 12 states and Puerto Rico was 6.1\% (95\% CI: 5.3-7.0\%). About 6 \% (5.7, 95\% CI: 4.9-6.6\%) reported medical cost as a barrier to seeking health care when needed in the past 12 months. Table 1 describes the overall characteristics of older adults, the weighted prevalence of reporting medical cost as a barrier to seeking health care and the weighted prevalence of current depressive symptoms along with the corresponding 95\% confidence intervals. The average age of older adults at the time of survey was 74.1 years [95\% CI: 73.9-74.4]. The majority of these adults were females (56.3\%), White Non-Hispanic (77.5\%), and more than three-fourth of them were either retired or unable to work. A little less than half of the older adults were unmarried (48.3\%), and had more than high school education (44.6\%). A little over one-fourth of the older adults reported "fair/poor" general health (28.8\%), almost $80 \%$ of them had at least one chronic condition other than current depression, were predominantly nonsmokers (91.2\%), and did not use any special equipment due to a health problem (81.0\%). The majority of older adults in the 12 states and Puerto Rico reported having a health plan $(97.9 \%)$, having a primary care provider (94.7\%), and having an annual health checkup (87.1\%).

\section{Significant sub-groups of older adults with medical cost as a barrier to seeking health care}

Among the different covariates examined for significant differences in the proportion of older adults who reported medical cost as a barrier to seeking health care when needed in the past 12 months, the following subgroups of individuals were significantly higher in proportion to report medical cost as a barrier to seeking health care compared to some of the older adults who reported medical cost not being a barrier to seeking health care: $i$ ) Hispanics vs. White non-Hispanics ( $11.7 \%$ vs. $4.3 \%)$; ii) Black non-Hispanics vs. White non-Hispanics $(10.1 \%$ vs. $4.3 \%)$; iii) older adults with no college education vs. those with some college education $(7.2 \%$ vs. $3.9 \%)$; iv) those who reported "Fair/Poor" general health vs. those with "Excellent/Very Good/Good" general health (10.4\% vs. $3.8 \%) ; v$ ) those with 3 or more chronic conditions other than current depression vs. those with no chronic conditions $(8.2 \%$ vs. $3.8 \%)$; vi) smokers vs non-smokers (11.3\% vs. $5.2 \%)$; vii) those who reported use of special equipment due to a health condition vs. those who did not use (10.0\% vs. $4.7 \%)$; viii) those with no health plan vs. those with a health plan ( $27.3 \%$ vs. $5.2 \%) ; i x)$ those with no primary care provider vs. those with a primary care provider ( $11.8 \%$ vs. $5.4 \%)$; and $x$ ) those who reported not having an annual health checkup vs. those who did ( $11.4 \%$ vs. $4.9 \%)$. There was no significant difference in the average age of older adults who reported medical cost as a barrier to seeking health care when compared to those who did not report medical cost as a barrier ( 73.0 years vs. 74.2 years).

\section{Significant sub-groups of older adults with current depressive symptoms}

Females were significantly higher in proportion to report symptoms of current depression compared to males (7.4\% vs. $4.6 \%)$. Among the sub-groups of individuals who reported medical cost as a barrier to seeking health care, the following also reported symptoms of current depression: $i$ ) Hispanics vs. White non-Hispanics (11.0\% vs. $5.6 \%)$; ii) those who reported "Fair/Poor" general health vs. those with "Excellent/Very Good/Good" general health $(14.3 \%$ vs. $2.8 \%)$; iii) those with 3 or more chronic conditions other than current depression vs. those with no chronic conditions $(11.5 \%$ vs. $2.8 \%)$; iv) smokers vs non-smokers ( $10.8 \%$ vs. $5.7 \%)$; and $v)$ those who reported use of special equipment due to a health condition vs. those who did not use ( $15.5 \%$ vs. $4.0 \%)$. Interestingly, older adults with a health plan were significantly higher in proportion for symptoms of current depression compared to those without a health plan $(6.2 \%$ vs. 3.3\%). Average age between individuals with and without symptoms of current depression was not significant (73.8 years vs. 74.1 years).

\section{Model based odds ratios for symptoms of current depression}

The prevalence of symptoms of current depression among older adults who reported medical cost as a barrier to seeking health care was significantly higher $[17.8$, 95\% CI: (11.4-21.1\%)] when compared to older adults who reported medical cost not being a barrier to seeking health care [5.5, 95\% CI: (4.7-6.2\%)]. After adjusting for all covariates of interest, older adults who reported medical cost as a barrier to seeking health care were more than twice likely to report current depressive symptoms compared to older adults who reported medical cost not being a barrier to seeking health care (Adjusted Odds Ratio (AOR): 2.2 [95\% CI: 1.53.3]) (Table 2). Additional file 1: Table S1 provides additional details on possible potential confounders we adjusted for in determining the association between medical cost as a barrier to seeking health care and current depressive symptoms in older adults. 
Table 1 Characteristics of Adults Aged 65 and Older $(n=24,018)$

\begin{tabular}{|c|c|c|c|c|c|c|c|}
\hline \multirow{2}{*}{ Socio-demographics } & \multirow[t]{2}{*}{ Unweighted n } & \multicolumn{2}{|c|}{$\begin{array}{l}\text { Overall } \\
\text { Mean or Proportion (95\% Cl) }\end{array}$} & \multicolumn{2}{|c|}{$\begin{array}{l}\text { Yes, Medical Cost a Barrier } \\
\text { to Health Care } \\
\text { Mean or Proportion }(95 \% \mathrm{Cl})\end{array}$} & \multicolumn{2}{|c|}{$\begin{array}{l}\text { Current Depressive } \\
\text { Symptoms (PHQ-8 Score } \geq 10) \\
\text { Mean or Proportion }(95 \% \mathrm{Cl})\end{array}$} \\
\hline & & & & & & & \\
\hline Age in years & 24018 & 74.1 & (73.9-74.4) & 73.0 & $(72.1-74.0)$ & 73.8 & $(72.2-75.4)$ \\
\hline \multicolumn{8}{|l|}{ Gender } \\
\hline Male & 8457 & 43.7 & $(42.0-45.4)$ & 4.7 & $(3.5-5.8)$ & 4.6 & $(3.6-5.6)$ \\
\hline Female & 15561 & 56.3 & $(54.6-57.9)$ & 6.5 & $(5.3-7.7)$ & 7.4 & $(6.1-8.6)$ \\
\hline \multicolumn{8}{|l|}{ Ethnicity } \\
\hline White Non-Hispanic & 20135 & 77.5 & (76.0-79.0) & 4.3 & $(3.5-5.2)$ & 5.6 & $(4.7-6.4)$ \\
\hline Black Non-Hispanic & 1479 & 7.7 & $(6.7-8.7)$ & 10.1 & $(6.6-13.6)$ & 5.1 & $(2.9-7.3)$ \\
\hline Hispanic & 1785 & 11.9 & $(10.8-13.1)$ & 11.7 & $(8.0-15.3)$ & 11.0 & $(7.4-14.6)$ \\
\hline Others $^{b}$ & 619 & 2.9 & $(2.2-3.5)$ & 6.3 & $(3.7-8.9)$ & 4.8 & $(1.8-7.9)$ \\
\hline \multicolumn{8}{|l|}{ Marital Status } \\
\hline Married & 11330 & 51.7 & $(50.1-53.4)$ & 4.7 & $(3.6-5.8)$ & 5.0 & $(4.0-6.0)$ \\
\hline Unmarried $^{c}$ & 12688 & 48.3 & $(46.6-49.9)$ & 6.8 & $(5.5-8.1)$ & 7.4 & $(6.0-8.8)$ \\
\hline \multicolumn{8}{|l|}{ Education } \\
\hline $\begin{array}{l}\text { Elementary/Some High School/ } \\
\text { High School Graduate }\end{array}$ & 11359 & 55.4 & $(53.8-57.0)$ & 7.2 & $(5.9-8.5)$ & 7.0 & $(5.7-8.3)$ \\
\hline $\begin{array}{l}\text { Some College or Technical School/ } \\
\text { College graduate }\end{array}$ & 12659 & 44.6 & $(43.0-46.2)$ & 3.9 & $(2.9-4.8)$ & 5.1 & $(4.1-6.1)$ \\
\hline \multicolumn{8}{|l|}{ Employment } \\
\hline Employed & 3520 & 13.6 & $(12.4-14.7)$ & 4.9 & $(2.9-6.8)$ & 5.4 & $(2.3-8.5)$ \\
\hline Unemployed $^{d}$ & 20498 & 86.4 & $(85.3-87.6)$ & 5.9 & $(4.9-6.8)$ & 6.3 & $(5.4-7.1)$ \\
\hline \multicolumn{8}{|l|}{ Health Indicators } \\
\hline \multicolumn{8}{|l|}{ General Health } \\
\hline Excellent/Very Good/Good & 17903 & 71.2 & $(69.6-72.7)$ & 3.8 & $(3.0-4.7)$ & 2.8 & $(2.1-3.6)$ \\
\hline Fair/Poor & 6115 & 28.8 & $(27.3-30.4)$ & 10.4 & $(8.4-12.4)$ & 14.3 & $(12.1-16.6)$ \\
\hline \multicolumn{8}{|l|}{ Number of Chronic Conditions } \\
\hline 0 & 5123 & 20.9 & $(19.6-22.2)$ & 3.8 & $(2.4-5.2)$ & 2.8 & $(1.6-3.9)$ \\
\hline 1 & 7673 & 30.7 & $(29.2-32.2)$ & 5.1 & $(3.8-6.4)$ & 4.1 & $(2.6-5.6)$ \\
\hline 2 & 5719 & 24.4 & $(23.0-25.9)$ & 5.7 & $(3.9-7.5)$ & 6.4 & $(4.7-8.1)$ \\
\hline$\geq 3$ & 5503 & 23.9 & $(22.4-25.4)$ & 8.2 & $(6.0-10.4)$ & 11.5 & $(9.4-13.7)$ \\
\hline \multicolumn{8}{|l|}{ Smoking } \\
\hline Yes & 2103 & 8.8 & $(7.8-9.7)$ & 11.3 & $(6.1-16.4)$ & 10.8 & $(6.5-15.0)$ \\
\hline No & 21915 & 91.2 & $(90.3-92.2)$ & 5.2 & $(4.4-5.9)$ & 5.7 & $(5.0-6.5)$ \\
\hline \multicolumn{8}{|c|}{ Use of Special Equipment due to a Health Problem } \\
\hline Yes & 4531 & 19.0 & $(17.7-20.2)$ & 10.0 & $(7.4-12.4)$ & 15.5 & $(12.8-18.1)$ \\
\hline No & 19487 & 81.0 & $(79.8-82.3)$ & 4.7 & $(3.9-5.6)$ & 4.0 & $(3.2-4.8)$ \\
\hline \multicolumn{8}{|l|}{ Health Care Indicators } \\
\hline \multicolumn{8}{|l|}{ Have a Health Plan } \\
\hline Yes & 23626 & 97.9 & $(97.2-98.5)$ & 5.2 & $(4.4-6.0)$ & 6.2 & $(5.4-7.1)$ \\
\hline No & 382 & 2.1 & $(1.5-2.8)$ & 27.3 & $(13.1-41.5)$ & 3.3 & $(1.5-5.1)$ \\
\hline \multicolumn{8}{|l|}{ Have a Primary Care Provider } \\
\hline Yes & 22726 & 94.7 & (93.9-95.5) & 5.4 & $(4.5-6.2)$ & 6.2 & $(5.3-7.0)$ \\
\hline No & 1292 & 5.3 & $(4.5-6.1)$ & 11.8 & $(6.9-16.6)$ & 6.0 & $(3.1-8.7)$ \\
\hline
\end{tabular}


Table 1 Characteristics of Adults Aged 65 and Older $(n=24,018)$ (Continued)

\begin{tabular}{|c|c|c|c|c|c|c|c|}
\hline \multirow{2}{*}{\multicolumn{2}{|c|}{ Annual Health Checkup }} & \multicolumn{2}{|c|}{$\begin{array}{l}\text { Overall } \\
\text { Mean or Proportion }(95 \% \mathrm{Cl})\end{array}$} & \multicolumn{2}{|c|}{$\begin{array}{l}\text { Yes, Medical Cost a Barrier } \\
\text { to Health Care } \\
\text { Mean or Proportion }(95 \% \text { Cl) }\end{array}$} & \multicolumn{2}{|c|}{$\begin{array}{l}\text { Current Depressive } \\
\text { Symptoms (PHQ-8 Score } \geq 10 \text { ) } \\
\text { Mean or Proportion ( } 95 \% \mathrm{Cl} \text { ) }\end{array}$} \\
\hline & & & & & & & \\
\hline Yes & 20255 & 87.1 & $(86.0-88.1)$ & 4.9 & $(4.1-5.7)$ & 6.1 & $(5.2-6.9)$ \\
\hline No & 3763 & 12.9 & $(11.8-14.0)$ & 11.4 & $(7.8-15.1)$ & 6.6 & $(3.8-9.5)$ \\
\hline
\end{tabular}

\section{Predictors of reporting medical cost as a barrier to seeking health care}

According to the adjusted logistic regression model results, gender (females: AOR: 1.52 [95\% CI: 1.07-2.17]), ethnicity (Black non-Hispanics: AOR: 1.79 [95\% CI: 1.09-2.96]; Hispanics: AOR: 2.48 [95\% CI: 1.53-4.02]), education (less than college education: AOR: 1.49 [95\% CI: 1.05-2.10]), general health ("Fair / Poor": AOR: 2.12 [95\% CI: 1.42-3.17]), smoking status (smokers: AOR: 1.72 [95\% CI: 1.07-2.76]), having a health plan (No: AOR: 5.44 [95\% CI: 2.67-11.09]), getting an annual checkup (No: AOR: 2.82 [95\% CI: 1.91-4.17]), and use of special equipment due to a health problem (Yes: AOR: 1.64 [95\% CI: 1.13-2.39]) were significant predictors of reporting medical cost as a barrier to seeking health care (Table 3).

\section{Discussion}

\section{Study overview}

Broadly speaking, studies on depression in the elderly have focused either on its risk factors or associated increases in health care costs and utilization. The current study is unique as it represents the first study of its kind to report the prevalence of symptoms of current depression in a sample of community dwelling older adults $(\geq$ 65 years of age) in the U.S. who self-reported medical cost as a barrier to seeking health care. In addition, this study examined the association between self-reported medical cost as a barrier to seeking health care and current depressive symptomatology and identified the socio-demographic characteristics of older adults who had a significantly higher likelihood to report medical cost as a barrier to seeking health care. The findings from this study highlight the need for effective interventions to address the barriers to seeking health care due to the burden of out-of-pocket medical cost on the individual, particularly for those with multiple chronic conditions. This may help minimize the risk for current depression in older adults.

\section{Main findings}

Based on data from the 2011 BRFSS, the prevalence of symptoms of current depression in a sample of community dwelling older adults ( $\geq 65$ years of age) in the U.S. was $6.1 \%$. This prevalence is higher than previously reported based on data from 2006 BRFSS using similar criteria (score $\geq 10$ on PHQ-8) for current depressive symptoms [28]. The prevalence of current depressive symptomatology was significantly higher (17.8\%) among older adults who reported medical cost as a barrier to seeking health care when compared to older adults who did not report medical cost as a barrier (5.5\%). After adjusting for all covariates, we found that older adults who reported medical cost as a barrier to seeking health care were twice more likely to report current depressive symptoms compared to those who did not report medical cost as a barrier to seeking health care. In addition, we also found that older adults with the following sociodemographics: females, Black non-Hispanics, Hispanics, and high school or less education; health indicators: "Fair/Poor" general health, smokers, and use of special equipment due to a health problem; and health care indicators: not having a health plan, and no annual checkup, were significantly more likely to report medical cost as a barrier to seeking health care. This finding is consistent with prior studies that have identified sociodemographic characteristics associated with out-ofpocket medical cost $[15,31,32]$.

Table 2 Prevalence of and Estimated Odds Ratio (95\% Cl) for Current Depressive Symptoms (PHQ-8 Score $\geq 10$ )

\begin{tabular}{|c|c|c|c|c|}
\hline & Unweighted n & $\%(95 \% \mathrm{Cl})$ & UOR $(95 \% \mathrm{Cl})$ & $\mathrm{AOR}(95 \% \mathrm{Cl})$ \\
\hline \multicolumn{5}{|c|}{ Was there a time in the past 12 months when you needed to see a doctor but could not because of cost? } \\
\hline Yes & 1062 & $17.8(11.4-24.1)$ & $3.7(2.4-5.9)$ & $2.2(1.5-3.3)$ \\
\hline No & 22956 & $5.5(4.7-6.2)$ & Reference & Reference \\
\hline
\end{tabular}

\%: Prevalence, UOR Unadjusted Odds Ratio

AOR Adjusted Odds Ratio. Adjusted for age, gender, ethnicity, marital status, education, employment, number of chronic conditions, smoking, general health status, having a health plan, having a primary care provider, annual health checkup, and use of special equipment due to a health problem 
Table 3 Predictors of Reporting Medical Cost as a Barrier to Seeking Health Care among Adults Aged 65 and Older ( $n=24,018)$

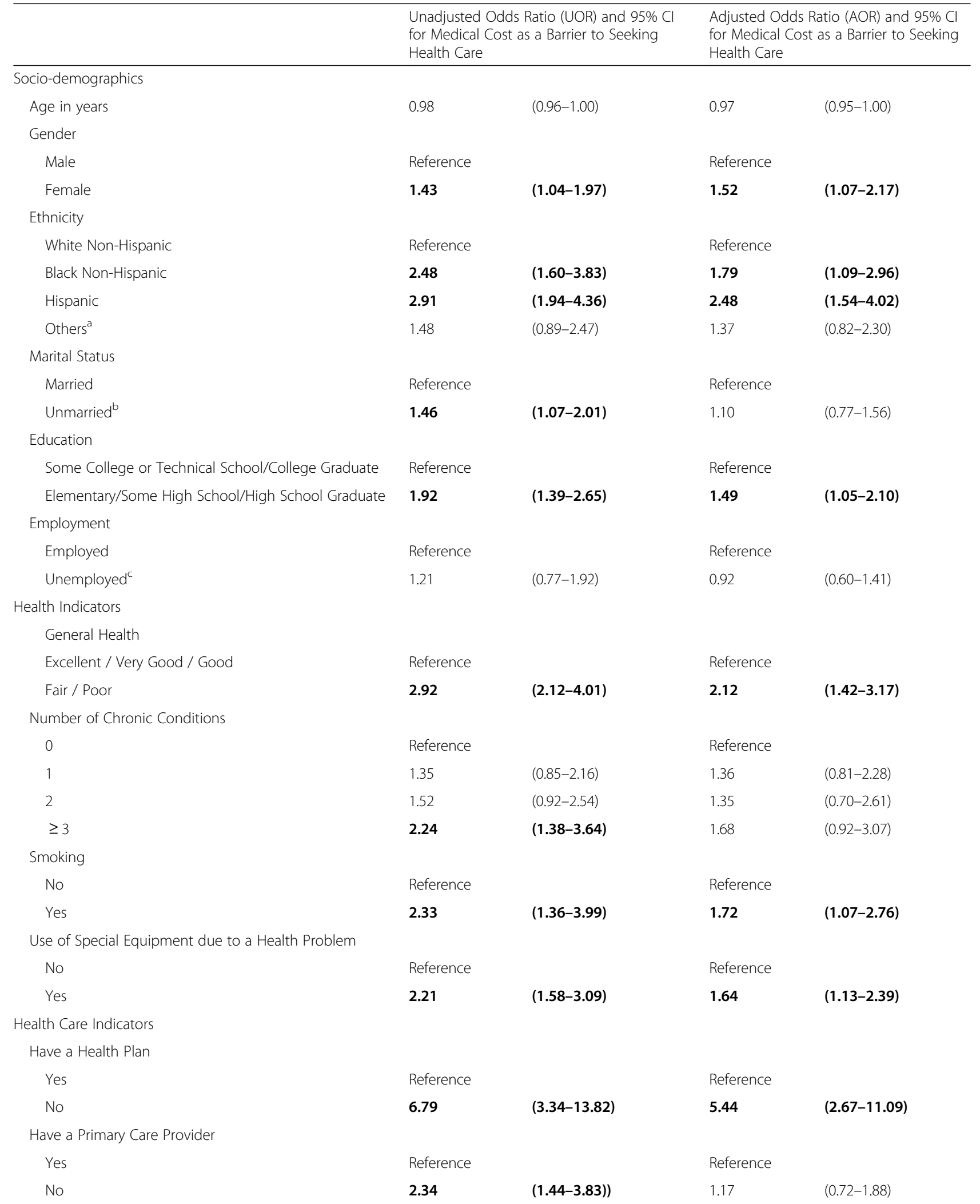


Table 3 Predictors of Reporting Medical Cost as a Barrier to Seeking Health Care among Adults Aged 65 and Older ( $n=24,018)$ (Continued)

\begin{tabular}{cll}
\hline & $\begin{array}{l}\text { Unadjusted Odds Ratio (UOR) and 95\% Cl } \\
\text { for Medical Cost as a Barrier to Seeking } \\
\text { Health Care }\end{array}$ & $\begin{array}{l}\text { Adjusted Odds Ratio (AOR) and 95\% Cl } \\
\text { for Medical Cost as a Barrier to Seeking } \\
\text { Health Care }\end{array}$ \\
\hline $\begin{array}{l}\text { Annual Health Checkup } \\
\text { Yes }\end{array}$ & $\begin{array}{l}\text { Reference } \\
\text { No }\end{array}$ & $\begin{array}{l}\text { Reference } \\
\mathbf{2 . 5 3}\end{array}$ \\
\hline
\end{tabular}

Includes non-Hispanic Asian, Native Hawaiian or other Pacific Islander, American Indian or Alaskan Native only, Multiracial and other race only

${ }^{b}$ Includes Divorced, Widowed, Separated, Never Married, and Member of an unmarried couple

Includes Homemaker, Student, Retired, Unable to Work, and Out of work

Statistical signifiance at $5 \%$ alpha is indicated by odds ratios in bold

\section{Association between medical cost as a barrier to seeking health care and symptoms of current depression}

One of the most common barriers to seeking health care is out-of-pocket medical cost [33]. In particular, among older adults with chronic conditions, the burden of out-of-pocket medical cost is a major concern [34-36]. In this current study, though out-of-pocket health care expenses was not measured, consistent with previous studies [19, 37-39], we found that the proportion of older adults who reported medical cost as a barrier to seeking health care increased with the number of chronic conditions (Table 1). A plausible explanation could be that a significant proportion of medical cost may have to do with out-of-pocket expenses for medications and prescription drugs often required to manage chronic conditions [34-36, 39].

Empirical evidence presented in the current study suggests that the burden of out-of-pocket medical cost is significantly associated with symptoms of current depression, thus, taking a step further in our understanding of the consequences of out-of-pocket medical cost (cost-sharing) burden among older adults. This finding is consistent with previous studies which reported the association between financial strain in general and symptoms of depression among older adults [23, 24].

Several studies have reported that lack of health care coverage or type of coverage (e.g., Medicare only) would lead to high financial burden [19, 36, 40]. This finding was consistent in our study with $27.3 \%$ reporting medical cost as a barrier for seeking health care among those without a health plan compared to $5.2 \%$ reporting the same among those with a health plan. However, despite having a health plan, the unadjusted prevalence of symptoms of current depression among older adults who reported medical cost as a barrier for seeking health care was $18.8 \%$ [95\% CI: 11.8-25.7\%]. Whereas among older adults without a health plan, the unadjusted prevalence of symptoms of current depression among those who reported medical cost as a barrier for seeking health care was 8.6\% [95\% CI: 2.2-15.0\%]. This could be because older adults with a health plan are more likely to utilize health care and as a result might have to sustain more out-of-pocket expenses compared to those without a health plan.

While we don't have specific information about the type of health plan, to understand the extent to which having a health plan mitigates the association between the burden of out-of-pocket medical cost and the likelihood to report current depression after controlling for all socio-demographic and health related factors, we examined the magnitude of this association stratified by health plan status. Among older adults who reported having a health plan, after adjusting for possible potential confounders, older adults who reported medical cost as a barrier for seeking health care were more than twice as likely to report current depression compared to those who reported medical cost not being a barrier for seeking health care [AOR: 2.2 [95\% CI: 1.5-3.4]); whereas among those who reported not having a health plan, the magnitude of this association was much augmented [AOR: 7.3 [95\% CI: 2.2-22.4]). This finding suggests that the burden of out-of-pocket medical cost is significantly associated with symptoms of current depression though the magnitude of this association could be mitigated due to having a health plan. As the prevalence of individuals with persistently high medical cost burden is likely to surge in the future [34], policies to reduce the burden of out-of-pocket medical cost among older adults may help address depression to some extent among the elderly and thereby reduce health care costs associated with depression.

\section{Strengths and limitations}

Although this study documents, using a nationally representative sample, a significant association between the individuals' burden of medical cost for health care and symptoms of depression among older adults, these findings are subject to limitations:

- The cross-sectional nature of the BRFSS data precludes us from drawing any causal relationship 
between the burden of medical cost and symptoms of current depression.

- BRFSS data are based on self-report and therefore may be subject to recall-bias for certain types of responses.

- Analysis of data in this study did not consider social and emotional support system among older adults. It is likely that social isolation in older adults might be a contributing factor to individual's mental health $[41,42]$. In addition, the analysis did not account for annual income; approximately 1 out of 7 older adults reported as employed during the time of the survey.

- Information about having a health plan was binary (Yes / No). Information about the type of health plan (e.g., types of insurance coverage) would have shed more light into the relationship between the burden of medical cost for health care and symptoms of current depression.

- Finally, since the data used in the current study are from 12 states in the 2011 BRFSS survey and is limited to non-institutionalized older adults, the findings may not be generalizable to all older adults in the U.S.

Despite these limitations, this study documents an important finding that has policy implications. To the best of our knowledge, this is the first study to report a significant association between individuals' burden of medical cost for health care and symptoms of depression.

\section{Conclusions}

In conclusion, findings from this study suggest that older adults ( $\geq 65$ years of age) who experience the burden of medical cost for health care are significantly more likely to report symptoms of depression. Having a health plan might help mitigate the association between burden of medical cost for health care and symptoms of depression. Health care professionals and policymakers should consider effective interventions to improve access to health care among older adults. Such efforts may help address the mental health concerns such as depression among the elderly and thereby reduce the cost burden associated with it and improve health outcomes. Further research is necessary to confirm the findings from this study and to understand how older adults manage their comorbid conditions which puts on them a huge burden of out-of-pocket medical cost to deal with.

\section{Additional file}

Additional file 1: Table S1. Estimated Odds Ratio (95\% Cl) for Current Depressive Symptoms (PHQ-8 Score $\geq 10$ ) among Adults Aged 65 and Older $(n=24,018)$. (DOCX $20 \mathrm{~kb})$

\section{Abbreviations}

AOR: Adjusted Odds Ratio; BRFSS: Behavioral Risk Factors Surveillance System; CDC: Centers for Disease Control and Prevention; U.S: United States;

UOR: Unadjusted Odds Ratio

\section{Acknowledgements}

The authors would like to acknowledge the participants in the 2011 BRFSS survey.

\section{Author's contributions}

VKC conceptualized and designed the study, designed the analytic plan, conducted the analyses, drafted, reviewed and revised the manuscript, and approved the final manuscript as submitted. ETC conducted the initial analyses, reviewed and revised the manuscript, and approved the final manuscript as submitted.

\section{Funding}

No external funding was secured for this study.

Availability of data and materials

Datasets can be obtained from the corresponding author on reasonable request.

\section{Ethics approval and consent to participate}

No administrative permissions were required to access the raw data. This study was exempt from review by Kent State University's IRB because BRFSS data are publicly available and deidentified.

\section{Consent for publication}

Not applicable.

\section{Competing interests}

The authors declare that they have no competing interests.

Received: 5 November 2018 Accepted: 8 July 2019

Published online: 18 July 2019

\section{References}

1. Gill J, Moore MJ. The State of aging \& health in America. Atlanta: Centers for Disease Control and Prevention; 2013

2. Ortman JM, Velkoff VA, Hogan H. US Census Bureau. An aging nation: the older population in the United States. Available at: https://www.census.gov/ prod/2014pubs/p25-1140.pdf. Accessed 9 Oct 2017.

3. Buttorff C, Ruder T, Bauman M. Multiple chronic conditions in the United States. Santa Monica: RAND Corporation; 2017.

4. Office of Disease Prevention and Health Promotion [ODPHP], Healthy People 2020. Older adults 2016.

5. Allan C, Valkanova V, Ebmeier K. Depression in older people is underdiagnosed. Practitioner. 2014;258(1771):19-22 2-3.

6. Manthorpe J, lliffe S. Depression in Later Life. London; Jessica Kingsley Publishers; 2005.

7. Blazer DG. Depression in late life: review and commentary. J Gerontol Ser A Biol Med Sci. 2003;58(3):M249-65.

8. Lopez AD, Murray CC. The global burden of disease, 1990-2020. Nat Med. 1998:4(11):1241.

9. Chang-Quan $\mathrm{H}$, et al. Health status and risk for depression among the elderly: a meta-analysis of published literature. Age Ageing. 2009;39(1):23-30.

10. Lenze EJ, et al. The association of late-life depression and anxiety with physical disability: a review of the literature and prospectus for future research. Am J Geriatr Psychiatry. 2001;9(2):113-35.

11. Prince MJ, et al. Social support deficits, loneliness and life events as risk factors for depression in old age. The gospel oak project VI. Psychol Med. 1997;27(2):323-32

12. Blazer $\mathrm{D}$, et al. The association of age and depression among the elderly: an epidemiologic exploration. J Gerontol. 1991;46(6):M210-5.

13. Harris T, et al. Predictors of depressive symptoms in older people-a survey of two general practice populations. Age Ageing. 2003;32(5):510-8.

14. Vink D, Aartsen MJ, Schoevers RA. Risk factors for anxiety and depression in the elderly: a review. J Affect Disord. 2008;106(1-2):29-44.

15. Crystal S, et al. Out-of-pocket health care costs among older Americans. J Gerontol Soc Sci. 2000;55(1):S5I-62. 
16. Goins RT, et al. Perceived barriers to health care access among rural older adults: a qualitative study. J Rural Health. 2005;21(3):206-13.

17. Goldman DP, Zissimopoulos JM. High out-of-pocket health care spending by the elderly. Health Aff. 2003;22(3):194-202.

18. Piette JD, Heisler M, Wagner TH. Problems paying out-of-pocket medication costs among older adults with diabetes. Diabetes Care. 2004;27(2):384-91.

19. Schoenberg NE, et al. Burden of common multiple-morbidity constellations on out-of-pocket medical expenditures among older adults. Gerontologist. 2007;47(4):423-37.

20. Bock J-O, et al. Impact of depression on health care utilization and costs among multimorbid patients-results from the multicare cohort study. PLoS One. 2014;9(3):e91973.

21. Kalsekar I, et al. The effect of depression on health care utilization and costs in patients with type 2 diabetes. Manag Care Interface. 2006;19(3):39-46.

22. Welch CA, et al. Depression and costs of health care. Psychosomatics. 2009; 50(4):392-401

23. Krause N. Chronic financial strain, social support, and depressive symptoms among older adults. Psychol Aging. 1987;2(2):185.

24. Mendes De Leon CF, Rapp SS, Kasl SV. Financial strain and symptoms of depression in a community sample of elderly men and women: a longitudinal study. J Aging Health. 1994;6(4):448-68.

25. Remler DK, Greene J. Cost-sharing: a blunt instrument. Annu Rev Public Health. 2009;30:293-311.

26. Baird KE. The financial burden of out-of-pocket expenses in the United States and Canada: How different is the United States? SAGE Open Med. 2016:4:2050312115623792.

27. Centers for Disease Control and Prevention. Behavioral Risk FactorSurveillanceSystem operational and user's guide. Version 3.0. Available at: https://www.cdc.gov/brfss/pdf/userguide.pdf. Published March 4, 2005. Accessed 19 Nov 2017

28. McGuire LC, et al. The patient health questionnaire 8: current depressive symptoms among US older adults, 2006 behavioral risk factor surveillance system. Am J Geriatr Psychiatry. 2009;17(4):324-34

29. Kroenke K, et al. The PHQ-8 as a measure of current depression in the general population. J Affect Disord. 2009:114(1-3):163-73.

30. Frances A, Pincus HA, First M. Diagnostic and statistical manual of mental disorders: DSM-IV. Washington DC: American Psychiatric Association; 1994

31. Davidoff AJ, et al. Out-of-pocket health care expenditure burden for Medicare beneficiaries with cancer. Cancer. 2013;119(6):1257-65.

32. Desmond K, Rice T, Cubanski J, Neuman P. The burden of out-of-pocket health spending among older versus younger adults: Analysis from the consumer expenditure survey, 1998-2003. Medicare Issue Brief. No. 7686. Menlo Park, C.A.: Kaiser Family Foundation; 2007.

33. Fitzpatrick $A L$, et al. Barriers to health care access among the elderly and who perceives them. Am J Public Health. 2004;94(10):1788-94.

34. Cunningham PJ. Chronic burdens: the persistently high out-of-pocket health care expenses faced by many Americans with chronic conditions, vol. 63. New York: Commonwealth Fund: 2009

35. Hwang $W$, et al. Out-of-pocket medical spending for care of chronic conditions. Health Aff. 2001:20(6):267-78.

36. Sambamoorthi U, Shea D, Crystal S. Total and out-of-pocket expenditures for prescription drugs among older persons. Gerontologist. 2003;43(3):345-59.

37. Soni A. Out-of-Pocket Expenditures for Adults with Health Care Expenses for Multiple Chronic Conditions, US Civilian Noninstitutionalized Population, 2014. Statistical brief \#498. Rockville: Agency for Healthcare Research and Quality; 2017.

38. Paez KA, Zhao L, Hwang W. Rising out-of-pocket spending for chronic conditions: a ten-year trend. Health Aff. 2009;28(1):15-25.

39. Fahlman C, et al. Prescription drug spending for beneficiaries in the last Medicare plus choice year of life. J Palliat Med. 2006;9(4):884-93.

40. Johnson RW, Mommaerts C. Are health care costs a burden for older Americans? Retirement Policy Program Brief Series, vol. 26; 2009.

41. Oxman TE, et al. Social support and depressive symptoms in the elderly. Am J Epidemiol. 1992;135(4):356-68.

42. Santini $\mathrm{Zl}$, et al. The association between social relationships and depression: a systematic review. J Affect Disord. 2015;175:53-65.

\section{Publisher's Note}

Springer Nature remains neutral with regard to jurisdictional claims in published maps and institutional affiliations.

Ready to submit your research? Choose BMC and benefit from:

- fast, convenient online submission

- thorough peer review by experienced researchers in your field

- rapid publication on acceptance

- support for research data, including large and complex data types

- gold Open Access which fosters wider collaboration and increased citations

- maximum visibility for your research: over $100 \mathrm{M}$ website views per year

At BMC, research is always in progress.

Learn more biomedcentral.com/submissions 